\title{
Biomaterials
}

\section{Cytocompatibility and response of osteoblastic-like cells to starch-based polymers: effect of several additives and processing conditions}

\author{
M.E. Gomes ${ }^{\mathrm{a}, *}$, R.L. Reis ${ }^{\mathrm{a}}$, A.M. Cunha ${ }^{\mathrm{a}}$, C.A. Blitterswijk ${ }^{\mathrm{b}}$, J.D. de Bruijn ${ }^{\mathrm{b}}$ \\ ${ }^{a}$ Department of Polymer Engineering, Univ. of Minho, Campus de Gualtar, 4710-057 Braga, Portugal \\ ${ }^{\mathrm{b}}$ IsoTis bv., Prof. Bronkorstlaan 10, 3723 MB Bilthoven, The Netherlands
}

Received 28 July 2000; accepted 3 November 2000

\begin{abstract}
This work reports on the biocompatibility evaluation of new biodegradable starch-based polymers that are under consideration for use in orthopaedic temporary applications and as tissue engineering scaffolds. It has been shown in previous works that by using these polymers it is both possible to produce polymer/hydroxyapatite (HA) composites (with or without the use of coupling agents) with mechanical properties matching those of the human bone, and to obtain 3D structures generated by solid blowing agents, that are suitable for tissue engineering applications. This study was focused on establishing the influence of several additives (ceramic fillers, blowing agents and coupling agents) and processing methods/conditions on the biocompatibility of the materials described above. The cytotoxicity of the materials was evaluated using cell culture methods, according to ISO/EN 109935 guidelines. A cell suspension of human osteosarcoma cells (HOS) was also seeded on a blend of corn starch with ethylene vinyl alcohol (SEVA-C) and on SEVA-C/HA composites, in order to have a preliminary indication on cell adhesion and proliferation on the materials surface. In general, the obtained results show that all the different materials based on SEVA-C, (which are being investigated for use in several biomedical applications), as well as all the additives (including the novel coupling agents) and different processing methods required to obtain the different properties/products, can be used without inducing a cytotoxic behaviour to the developed biomaterials. (C) 2001 Elsevier Science Ltd. All rights reserved.
\end{abstract}

Keywords: Starch-based polymers Biodegradable; Polymers; Cytotoxicity; Orthopaedics

\section{Introduction}

Many degradable polymeric materials, both from natural and synthetic origin, have been investigated for use in medical applications [1]. The increased demands placed on biomaterials for both currently approved and novel emerging applications continue to fuel the interest in improving the performance of existing medical-grade polymers and for developing new polymeric systems.

The tissue engineering approach to repair and regenerate damaged tissues is based on the use of scaffolds, which act as supports for the regenerating tissue. Due to the broad range of potential tissue engineered systems,

\footnotetext{
*Corresponding author. Tel.: 351-253-604498; fax: 351-253-604492.
}

E-mail address: megomes@eng.uminho.pt (M.E. Gomes). there is a continuous search for materials that exhibit suitable properties, that can be tailored to several tissue systems [2].

Apart from favourable physico-chemical and mechanical properties, the most important requirement for a biodegradable polymer to be used in medical applications is its biocompatibility in a specific environment, together with the non-cytotoxicity of its degradation products [1]. In fact, one of the major problems in the use of synthetic degradable polymers as biomaterials is to make sure that they are biocompatible by themselves, and that the use of particular additives and/or processing technologies required to obtain different properties and or configurations, will not interfere with the biocompatible behaviour [1].

Cytotoxicity testing represents the initial phase in testing biocompatibility of potential biomaterials and medical devices. Its purpose is to act as a reliable, convenient, and reproducible screening method to detect at an early 
stage in the testing process cell death or other serious negative effects on cellular functions [3-8].

Cytotoxicity deals mainly with the substances that leach out of biomaterials. For example polymers often have low molecular weight "leachables" (additives, low molecular weight components, initiator fragments, etc.) that exhibit varying levels of physiologic activity and cell toxicity $[3,9]$. Therefore, the knowledge of the degradation processes of biodegradable polymeric biomaterials and of the effects that their degradation products might have on the body is crucial for long-term success of a biomaterial [10].

In fact, it is generally accepted that biocompatibility means not only absence of a cytotoxic effect but also positive effects in the sense of biofunctionality, i.e., promotion of biological processes which further the intended aim of the application of a biomaterial [11-13].

Biodegradable starch-based polymeric biomaterials have been suggested for a wide range of biomedical applications [14-16]. These polymers have shown to be biodegradable. The typical products of their degradation are lower molecular weight starch chains, fructose and maltose. More information on the degradation mechanisms relevant to these blends may be found elsewhere [17]. Depending on the synthetic component of the blend, processing methods, additives and reinforcement materials used, it is possible to obtain very distinct structure/properties combinations, with several different potential applications, for example, as tissue engineering scaffolds [14], as bone cements [15] or as hydrogels for controlled release of drugs [15], and as bone substitutes in the orthopaedic field [16].

This work presents a study on the influence of several additives/processing methods, used to obtain several structure/properties combinations, over the biocompatible behaviour of starch-based polymers. The biocompatibility was evaluated on cytotoxicity trials carried out using standardised test methods assays [18] and by studying the cell response of osteoblastic-like cells (HOS) to the starch-based composites.

\section{Materials \& methods}

\subsection{Processing of the starch based polymers}

The polymer used in this study was a corn starch/ethylene vinyl alcohol $(60 / 40 \mathrm{~mol} / \mathrm{mol})$ biodegradable blend (SEVA-C, Novamont, Italy). The typical amount of starch in this commercially available blend is $50-60 \%(\mathrm{wt} \%)$. The starch was obtained from corn and has a $70 / 30 \%$ (wt \%) amylopectin/amylose ratio. The porous structures were obtained by injection moulding of the polymer, previously mixed with a solid blowing agent in amounts of 5,10,15 and 20\% (wt\%). The blowing agent used is a master-batch based on carboxylic acids (trade name Hostalon P9947 from Hoechst, Germany), currently used in non-medical applications. This blowing agent reacts by heating, during processing, releasing $\mathrm{CO}_{2}$ and $\mathrm{H}_{2} \mathrm{O}$. To produce the composite materials, the polymer was reinforced with $10,20,30$ or $40 \%$ (wt $\%$ ) hydroxylapatite (HA, Plasma Biotal, UK), with $90 \%$ of the particles with a medium size around $7 \mu \mathrm{m}$ (laser granulometry). Furthermore, two different coupling agents are also being tested, for the first time in the biomaterials field [18], in order to improve the polymer/HA interface for achieving higher mechanical properties (matching the properties of human bone) and therefore allowing for their use in orthopaedic applications. These coupling agents are: a neoalkoxy titanate and a neoalkoxy zircanate, both obtained from KenReact, Bayonne, USA.

The polymer itself (without HA) was processed under different sets of conditions (temperature and back pressure), aimed at isolating, respectively, the effects of thermal and mechanical degradation during processing of HA-filled polymers, on the cytotoxicity of the polymers.

All the materials were injection moulded into ASTM dumb-bell samples of $2 \times 4 \mathrm{~mm}^{2}$ of cross section (total length of $60 \mathrm{~mm}$, of which $20 \mathrm{~mm}$ correspond to the testing region on a tensile experiment) in a Klockner Ferromatic FM-20. After processing, the samples were cut into $1 \times 1 \mathrm{~cm}^{2}$ pieces and subsequently sterilised by ethylene oxide prior to testing.

\subsection{Cytotoxicity assays}

The cytotoxicity of leachables of all materials was evaluated using cell culture methods, namely MEM extraction test $(72 \mathrm{~h})$ - short term and long term, according to ISO/EN 109935 guidelines [17]. UHMWPE (Goodfellow, UK) and latex rubber (Hilversumse Rubberhandel, NL) were used, respectively, as negative and positive control materials.

\subsubsection{Cell culture}

A cell line of mouse lung fibroblasts (L929) was selected for all the cytotoxicity assays. This cell line was grown as a confluent monolayer culture in $75 \mathrm{~cm}^{2}$ polystyrene flasks, using Dulbecco's modified Eagle's medium (DMEM, Gibco Life) supplemented with $10 \%$ foetal bovine serum (FBS, Gibco Life), 1\% Fungizone (Sigma) and $0.5 \%$ penicillin-streptomycin (Gibco Life). Cell culture atmosphere was $5 \% \mathrm{CO}_{2}$ in air; $24 \mathrm{~h}$ before starting each cytotoxicity test, the cells were trypsinised and cultured with a density of approximately 100,000 cells $/ \mathrm{ml}$, in order to establish a $80 \%$ confluent monolayer.

\subsubsection{MEM extraction test $(72 \mathrm{~h})$}

Extraction procedure: For all tests a constant ratio of outer surface to fluid volume, equal to $3 \mathrm{~cm}^{2} / \mathrm{ml}$, was 
Table 1

Quantitative and qualitative scores used in the cytotoxiciy tests. The four parameters are scored (0-4) and then combined to calculate a final cytotoxicity index (0-8) as described in the text

\begin{tabular}{lllll}
\hline Score & Confluency & Floating cells & Change of cellular morphology & $\begin{array}{l}\text { Inhibition of cell } \\
\text { growth }\end{array}$ \\
\hline 0 & $100 \%$ & $0 \%$ & No changes during test period & $0-10 \%$ \\
1 & $90-100 \%$ & $0-5 \%$ & $\begin{array}{l}\text { Slight changes, few cells affected } \\
\text { Mild changes, some cells }\end{array}$ & $\begin{array}{l}10-30 \% \\
\text { round/spindle shaped } \\
2\end{array}$ \\
$60-90 \%$ & $5-10 \%$ & $\begin{array}{l}\text { Moderate changes, many cells } \\
\text { round/spindle shaped }\end{array}$ & $50-70 \%$ \\
3 & $30-60 \%$ & $10-20 \%$ & $\begin{array}{l}\text { Severe changes, about all cells } \\
\text { show morphological changes }\end{array}$ \\
4 & $0-30 \%$ & $>20 \%$ & & $70-100 \%$ \\
\hline
\end{tabular}

used. In the short-term tests, the materials to test and the control materials were extracted for $24 \mathrm{~h}$ at $37^{\circ} \mathrm{C}$ and $60 \mathrm{rpm}$ (in a thermostatic bath), in the complete culture medium (the same used for cell culture).

Test culture: for the beginning of the tests, the culture medium in each well is replaced for the same amount $(2 \mathrm{ml})$ of extraction fluid. The extract of each material (test and control) was evaluated in three-fold. The plates were incubated at $37^{\circ} \mathrm{C}$ and with a $5 \% \mathrm{CO}_{2}$ atmosphere.

Evaluation: After 24, 48 and $72 \mathrm{~h}$ testing, the reaction of cells to the extracts was evaluated microscopically (in an inverted phase contrast optical microscope connected to a videoprinter), compared to the negative control and scored for the confluency of the monolayer, degree of floating cells and changes in cellular morphology (see scores on Table 1). At the end of the test (after $72 \mathrm{~h}$ ), the cells were detached from the culture wells by means of trypsinization; the percentage of growth inhibition was then determined by cell counting, using a hemacytometer and scored after correction for the value of the negative control.

Finally, the scores correspondent to these four quantitative and qualitative parameters (see again Table 1) are combined (the four parameters have equal weight, i.e., $25 \%$ ), resulting in a final cytotoxic response index ranging from 0 to 8 . The following criterion is then used to classify the reactivity of the materials:

$\begin{array}{ll}\text { Cytotoxicity index } & \text { Reactivity } \\ 0-1 & \text { none } \\ 1-3 & \text { slightly toxic } \\ 3-5 & \text { mildly toxic } \\ 5-7 & \text { moderately toxic } \\ 7-8 & \text { severely toxic }\end{array}$

For cytotoxicity index ranging from 0 to 3 , the material is considered to pass the cytotoxicity test, for index between 3 and 5 it is advised to repeat the test and for index higher than 5 the material is considered to fail the test.

\subsubsection{MEM long-term extraction test}

The long-term test was applied to evaluate the effects of degradation products resulting from longer degrada- tion periods on the cytotoxicity of the material, which may compromise the long-term implantation of the biomaterial.

Extraction procedure: for these tests, the materials were extracted for different periods, namely 4, 10, 20 and 40 days. It was used the same medium described for the cell culture, but in this case the FBS was only added to the medium before starting the test.

Test culture: as described for MEM short-term test.

Evaluation: as described for MEM short-term test.

\subsubsection{MEM extraction test after artificial ageing}

Cytotoxicity tests were also carried out after an artificial ageing procedure, prior to the normal $24 \mathrm{~h}$ extraction, in order to simulate higher degradation rates. This procedure consisted in the immersion of the test materials in a sterile phosphate buffer solution (PBS, $\mathrm{pH}=7.4$, Sigma) at $50^{\circ} \mathrm{C}$ and $60 \mathrm{rpm}$ for periods up to 30 days ( 3,15 and 30 days). After each period, the materials were removed from the PBS and rinsed with the extraction medium before the extraction procedure. These artificial ageing tests were performed based on a mass/volume ratio, where a gram of the test sample was immersed in $10 \mathrm{ml}$ of PBS.

Extraction procedure: as described for MEM shortterm test.

Test culture: as described for MEM short-term test.

Evaluation: as described for MEM short-term test.

\subsection{Direct contact tests with osteoblastic-like cells}

For studying other aspects of cytotoxicity, such as the ability of cells to adhere to the materials surface, a cell suspension of human osteosarcoma cells (HOS) was seeded on SEVA-C and SEVA-C composites with 10 and $30 \%$ of HA, for different periods. For these experiments, the HOS cells were cultured in MEM supplemented with $10 \%$ foetal bovine serum (FBS, Gibco Life), $1 \%$ of non-essential amino acids (NEEA, Gibco Life), 1\% L-glutamine and $0.5 \%$ penicillin-streptomycin (Sigma). 
The cells were seeded on the materials surface $\left(1 \times 1 \mathrm{~cm}^{2}\right)$ and on thermanox (control material) at a density of 10,000 cells $/ \mathrm{cm}^{2}$, for 2,5 and $16 \mathrm{~h}$. After each one of these periods of time, the samples were washed with warm PBS, fixed with $1.5 \%$ glutaraldeyde $\left(4^{\circ} \mathrm{C}\right)$ for at least 30 min, dehydrated to alcohol $100 \%$ and critical point dried. Finally the samples were sputter coated with gold and observed in a scanning electron microscope (SEM, Philips S525), for analysing the possible attachment or possible changes in the morphology of the HOS cells in contact with the materials.

\section{Results \& discussion}

All the composite materials have demonstrated a noncytotoxic behaviour both in the short-term and longterm cytotoxicity testing. The same materials, which were previously submitted to the artificial ageing procedure aimed at simulating longer implantation periods, have also passed (according to the criteria that was described before) the cytotoxicity tests. These results are very promising for the further application of the studied polymers.

However, it was observed an increase in growth inhibition for longer extraction periods (see Fig. 1) and also for longer incubation periods in PBS (see Fig. 2). Furthermore, and as it was previously reported [19], it can also be seen that higher amounts of HA in the composite materials produced an increased inhibitory effect in cells growth. Hydroxyapatite has been widely used on its own and as reinforcement material in the biomedical field, and there is no reason to believe that it could be inducing any cytotoxic effect on the starch-based composites. In fact it is well known that hydroxyapatite is biocompatible and osteoconductive.

Therefore, these results were at first related to the more severe processing conditions (higher shear stresses and viscous dissipation during the thermal cycles) needed to produce the composite materials, especially those with higher HA amounts. In fact, during the processing of the

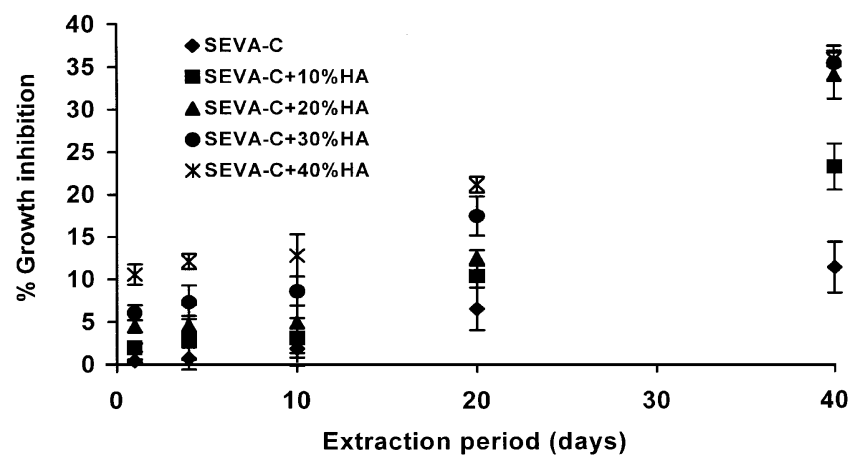

Fig. 1. Growth inhibition versus extraction period for SEVA-C and SEVA-C composites.

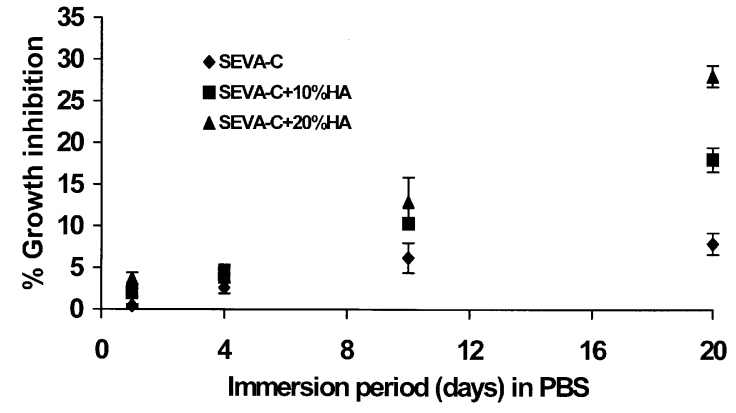

Fig. 2. Growth inhibition observed in the extracts of SEVA-C and SEVA-C composites after being submitted to an artificial ageing procedure for several different periods.

composite material, the presence of HA deeply increases the melt viscosity, making it necessary to use slightly higher temperatures and/or higher shear stresses in order to allow the normal flow of the polymer based melt. Furthermore, the presence of the stiff filler generates higher levels of viscous dissipation, leading to a higher rate of degradation of the thermal sensitive polymers that is responsible for the obtained results.

The effect of the processing conditions, namely the temperature and back pressure, on the growth inhibition of L929 cells in contact with the extracts of these materials was studied by testing samples of the polymer itself (without HA) processed under different sets of conditions. These experiments are aimed at isolating, respectively, the effects of thermal and mechanical degradation during processing of HA filled polymers. The results of these tests (displayed in Figs. 3 and 4) show that these conditions provoke the thermal-mechanical degradation of the materials leading to a greater concentration of leachables in contact with the cells (possible low molecular weight chains, which are easily leached out of the materials) and consequently to the decrease in cell proliferation. Comparing results displayed in Fig. 3 and 4, it can be easily concluded that the thermal degradation produces a much stronger effect in the inhibition of cell growth. Consequently, it might be concluded that special care should be taken when processing these systems, that are very sensitive to thermal degradation, as the processing conditions may strongly affect the biomaterials biocompatibility. This is an important conclusion that is not easily found on published works.

In this study it was also proved that the new coupling agents, which are very effective in providing a better interface between the polymeric matrix and the hydroxylapatite reinforcement, and thus in obtaining better mechanical performances [18] do not induce any toxic effect on L929 cells. These results are in contrast, for instance, with typically the bad results reported for the use of silane-based compatibilizers. Fig. 5 shows that after $72 \mathrm{~h}$ in contact with the extract of the composite material containing this coupling agent, a monolayer of 


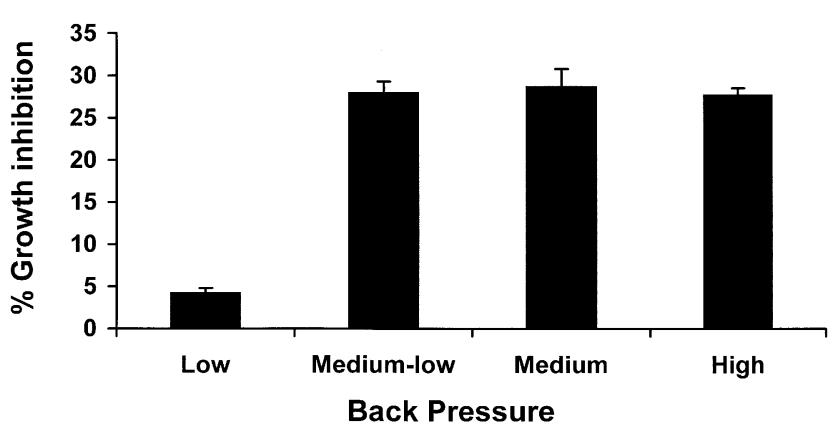

Fig. 3. Growth inhibition vs. backpressure values used to process SEVA-C.

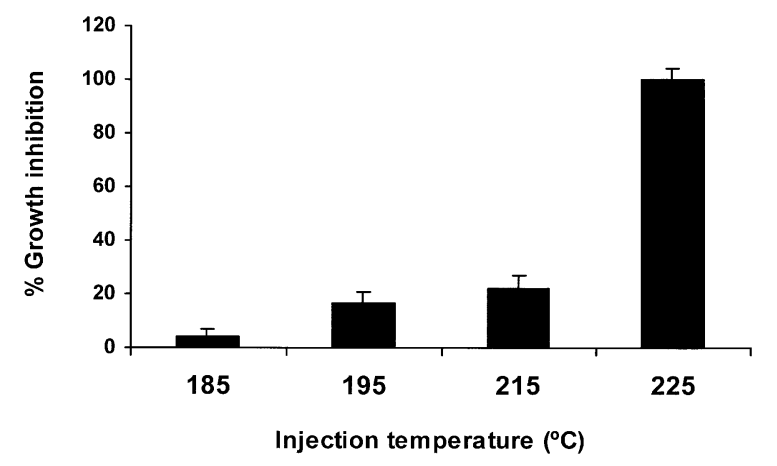

Fig. 4. Growth inhibition vs. melt temperature used to process SEVA-C.

cells with normal morphology was formed. This layer looks very similar to the cells in contact with the extract of the negative control.
The methodology proposed to produce the porous materials, i.e., the blowing agent used during the injection moulding process also seems not to have any negative effect in the non-cytotoxic behaviour of the starch-based polymer, since the cells in contact with extracts of these materials exhibit a normal morphology and proliferation, compared to the negative control. This blowing agent is commercially available but has not been used before to obtain biomedical products, therefore its cytotoxicity behaviour has never been evaluated. Furthermore, the faster degradation presented by these systems [14], when compared with the compact SEVA-C mouldings, was not responsible for any observable cytotoxicity. This manufacturing methodology, as well as its potential for the production of tissue engineering scaffolds, has been described in detail in previous works [14].

Finally, direct contact experiments were performed on starch-based polymers and composites, using osteoblastic-like cells in order to evaluate the cell/materials interaction with respect to cell adhesion and proliferation. The SEM analysis performed after 5 and $16 \mathrm{~h}$ of incubation, revealed that the response of the osteoblastic-like cells when in contact with the composites seems to be better than when in contact with the non-reinforced polymer. After only $5 \mathrm{~h}$ of incubation it was already possible to see some HOS cells on the surface of SEVA-C (Fig. 6a), which formed an almost confluent monolayer at the end of 16 days of incubation. However, the cells on the surface of the unreinforced material didn't seem to be very well attached even after the longer period of incubation $(16 \mathrm{~h})$, when compared to the composite materials
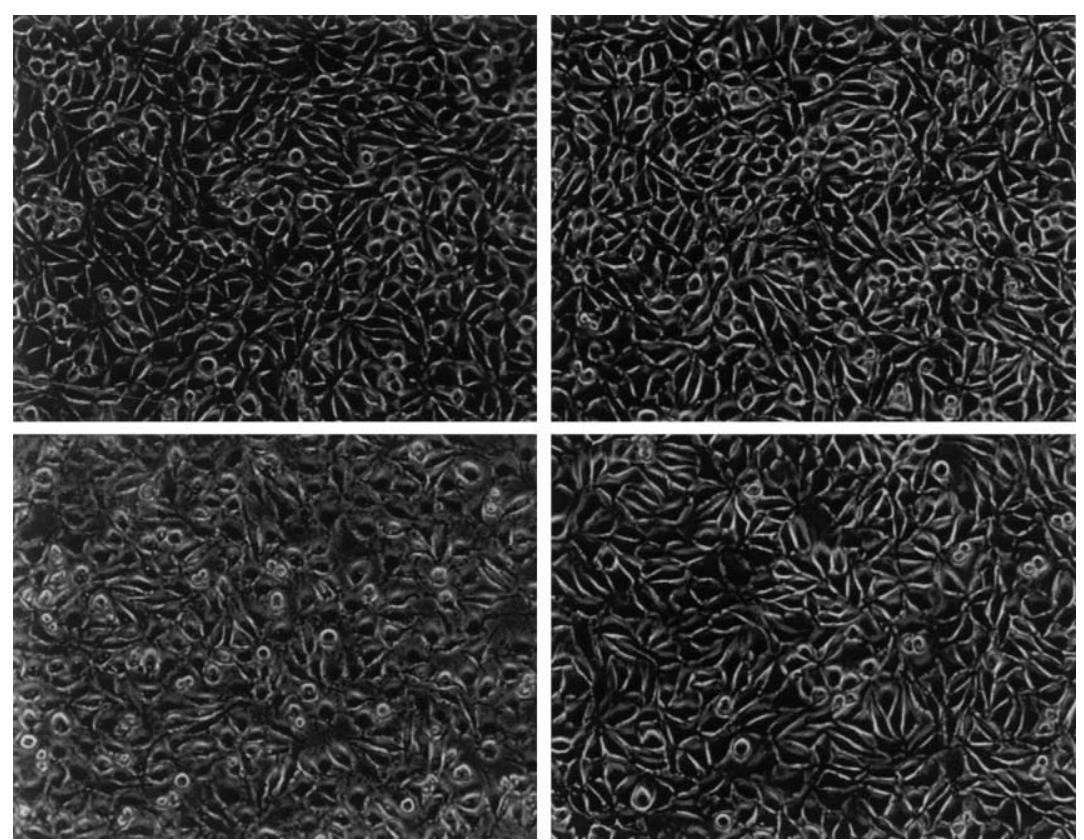

Fig. 5. L929 cells in contact with extracts of: (a) left top: negative control; (b) left bottom: positive control; (c) right top: composite material (SEVA-C + HA) coupled with neoalkoxy titanate; and (d) right bottom: composite coupled with neoalkoxy zircanate. 

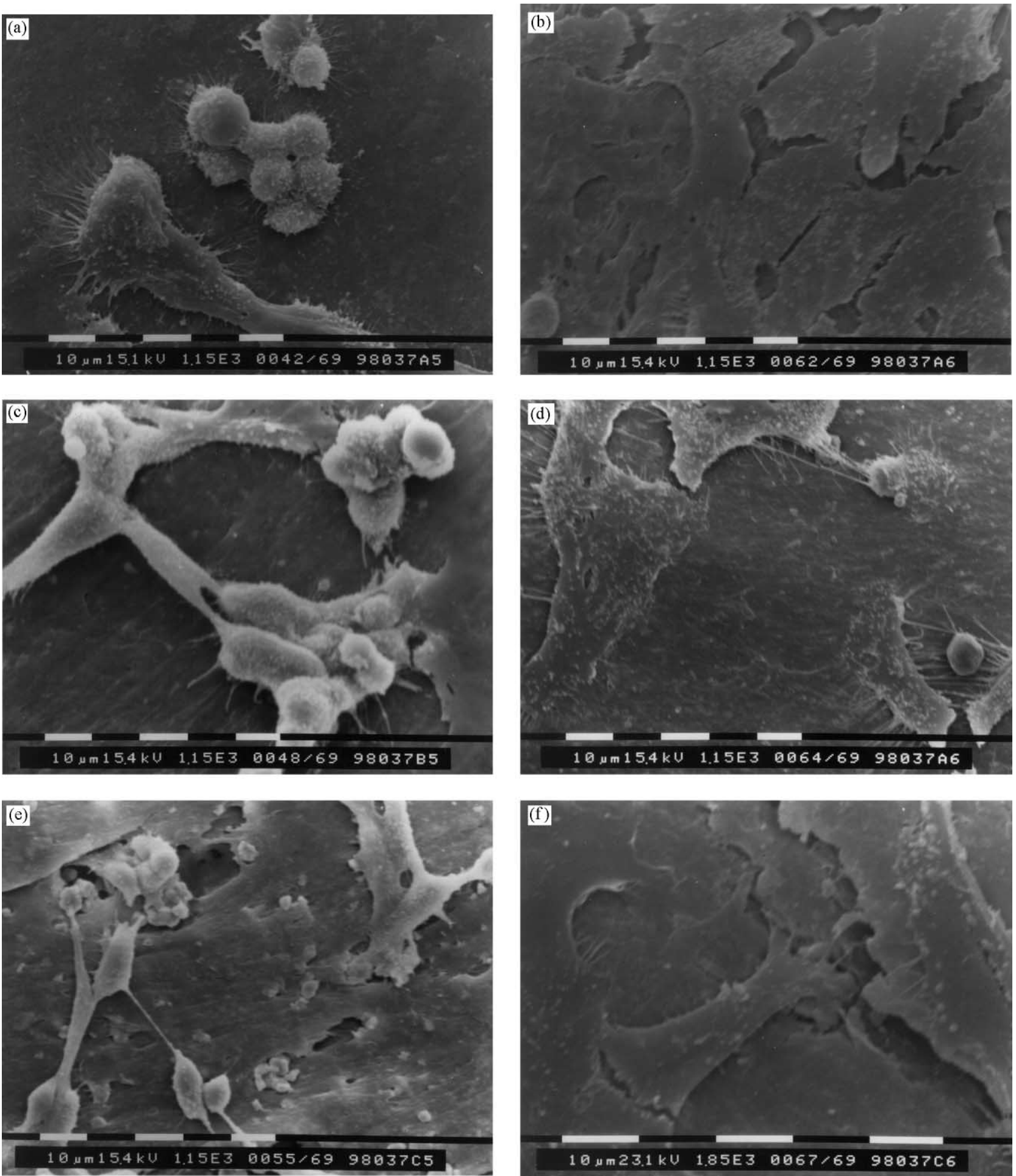

Fig. 6. SEM micrograph showing the HOS cells in contact with the surface of: (a) SEVA-C after $5 \mathrm{~h}$ incubation; (b) SEVA-C after $16 \mathrm{~h}$ incubation; (c) SEVA-C $+10 \%$ HA after $5 \mathrm{~h}$ incubation; (d) SEVA-C $+10 \%$ HA after $16 \mathrm{~h}$ incubation; (e) SEVA-C $+30 \%$ HA after $5 \mathrm{~h}$ incubation; and (f) SEVA$\mathrm{C}+30 \% \mathrm{HA}$ after $16 \mathrm{~h}$ incubation.

and to the thermanox. In contrast, the cells seeded on the composite materials are much flattened and better spread on the surface (Fig. 6c-f), and look similar to the cells cultured on thermanox.
It was observed that cell filapodia preferentially attached to HA particles which have come out to the surface of the composite materials, suggesting that these particles provided sites for cell attachment and 
stimulated cell proliferation. Consequently, the composites with higher amounts of HA, besides their improved mechanical properties, seem to have a more suitable biological behaviour, although the results from cytotoxicity tests seemed to indicate exactly the opposite. These results confirm that the higher growth inhibition obtained in the cytotoxicity tests for the materials reinforced with the HA, was not due to the presence of the HA itself, but to the thermo-mechanical degradation which results from the more severe conditions used during the processing of the composites, that lead to the leaching of higher amounts of low molecular weight compounds to the culture medium.

These results also evidence that the data obtained on cytotoxicity assays is not enough to obtain adequate knowledge on the biocompatibility of a biomaterial. It is necessary to test simultaneously other aspects of cell behaviour and cell function, that deal with the appropriate cell response to the presence of a biomaterials and combine results obtained in different types of assays. Only the integrated interpretation of complementary in vitro tests can allow for some extrapolation of what could be the in vivo behaviour of a newly proposed biomaterial.

\section{Conclusions}

The results obtained show that all the different materials based on SEVA-C, which are being investigated for use in medical applications, as well as all the additives (including the novel coupling and blowing agents) and processing methods required to obtain the different properties/products, can lead to a non-cytotoxic behaviour of the biomaterials. However, special care should be taken to avoid thermal degradation during processing, which can lead to an inhibition of cell proliferation. In addition, it was found that the composite materials seem to induce a good response, with respect to adhesion and proliferation, on osteoblastic-like cells, i.e., the cells which the implant will actually be facing in vivo, since successful adhesion on artificial surfaces is an important prerequisite for inducing bone formation at the site of implantation.

All these results are very promising for the future application of starch-based biodegradable polymers in the biomedical field, although, in order to have a fully understanding of the biocompatibility behaviour of starch-based polymers, it is important to further test these materials, in particular with respect to their ability to promote cell adhesion and proliferation and with respect to their behaviour on in vivo experiments.

\section{References}

[1] Pachence JM, Kohn J. Biodegradable polymers for tissue engineering. In: Lanza R, Langer R, Chick W, editors. Principles of tissue engineering. New York: Academic Press, 1997. p. 263-72.

[2] Madihally SV, Matthew HWT. Porous chitosan scaffolds for tissue engineering. Biomaterials 1999;20:1133-42.

[3] Kirkpatrick CJ. A critical view of current and proposed methodologies for biocompatibility testing: cytotoxicity in vitro. Regulatory Affairs 1992;4:13-32.

[4] Dekker A, Panfil C, Valdor M, Pennartz G, Richter H, Mittermayer C, Kirkpatrick CJ. Quantitative methods for in vitro cytotoxicity testing of biomaterials. Cel Mater 1994;4:101-12.

[5] Hanks CT, Wataha JC, Sun Z. In vitro models of biocompatibility: a review. Dent Mater 1996;12:186-93.

[6] Kirkpatrick CJ, Mittermayer C. Theoretical and practical aspects of testing potential biomaterials in vitro. J Mater Sci: Mater Med 1990;1:9-13.

[7] Pizzoferrato A, Ciapetti G, Stea S, Cenni E, Arciola CR, Granchi D, Savarino L. Cell culture methods for testing biocompatibility. Clin Mater 1994;15:173-90.

[8] Oliva A, Salerno A, Locardi B, Riccio V, Ragione FD, Iardino P, Zappia V. Behaviour of human osteoblasts cultured on bioactive glass coatings. Biomaterials 1998;19:1019-102.

[9] Ratner BD. Biomaterials science: overview and opportunities with special reference to organic and polymeric glow discharge plasma treatments. In: d' Agostino $r$ et al., editors. Plasma processing of polymers. Dordrecht: Kluwer Academic Publishers, 1997. p. 453-64.

[10] Wake MC, Gerecht PD, Lu L, Mikos AG. Effects of biodegradable polymer particles on rat marrow-derived stromal osteoblasts in vitro. Biomaterials 1998;19:1255-68.

[11] Kirkpatrick CJ, Bittinger F, Wagner M, Kohler H, van Kooten TG, Klein CL, Otto M. Current trends in biocompatibility testing. Proc Instn Mech Engrs 1998;212:75-84.

[12] Kooten TG, Klein CL, Kohler H, Kirkpatrick CJ, Williams DF, Eloy F. From cytotoxicity to biocompatibility testing in vitro: cell adhesion molecule expression defines a new set of parameters. J Mater Sci: Mater Med 1997;8:835-41.

[13] Yamamoto A, Mishima S, Maruyama N, Sumita M. A new thecnique for direct measurement of shear force necessary to detach a cell from a material. Biomaterials 1998;19:871-9.

[14] Gomes ME, Malafaya P, Ribeiro A, Reis RL, Cunha AM. A new approach based on injection moulding to produce starch based biodegradable scaffolds: morphology, mechanical and degradation behaviour. Biomaterials 2000;22:883-9.

[15] Pereira CS, Cunha AM, Reis RL, Vázquez B, San Roman J. New starch-based thermoplastic hydrogels for use as bone cements or drug-delivery carriers. J Mater Sci: Mater Med 1998;9: 825-33.

[16] Reis RL, Cunha AM, Bevis MJ. Using non-conventional processing routes to develop anisotropic and biodegradable composites of starch based thermoplastics reinforced with bone-like ceramics. J Appl Med Polyn 1998;2:49-53.

[17] ISO/EN 10993-5. Biological evaluation of medical devices-Part 5 tests for cytotoxicity, in vitro methods: 8.2 tests on extracts.

[18] Mendes S, Bovell Y, Reis R, van Blitterswijk C, de Bruijn J. Biocompatibility testing of novel starch based polymers and composites with potential application in orthopaedic surgery. Biomaterials 2001, in press.

[19] Vaz CM, Cunha AM, Reis RL. Degradation model of starchEVOH/HA composites. Mater Res Innov 2001, in press. 